\title{
Optimism is associated with respiratory symptoms and functional status in chronic obstructive pulmonary disease
}

\author{
Hyeon-Kyoung Koo ${ }^{1,2}$, Karin F. Hoth ${ }^{3}$, Barry J. Make ${ }^{4}$, Elizabeth A. Regann ${ }^{4}$, James D. Crapo ${ }^{4}$, \\ Edwin K. Silverman ${ }^{1,5}$ and Dawn L. DeMeo ${ }^{1,5^{*}}$
}

\begin{abstract}
Background: Optimism is the general belief that good things will occur in the future; optimism is modifiable by cognitive behavioral therapy (CBT). Previous studies have associated higher optimism with improved health outcomes and lower all-cause mortality.

Research question: Investigate association between optimism and disease-related characteristics in chronic obstructive pulmonary disease (COPD).

Study design and methods: Current and former smokers with/without COPD and Preserved Ratio Impaired Spirometry (PRISm) from the 10-year follow-up visit for the Genetic Epidemiology of COPD (COPDGene) study were included. Optimism was assessed at the 10-year visit using the Life Orientation Test-Revised. Models of optimism as a predictor of lung function, COPD-associated phenotypes including exacerbations, and functional assessments, were adjusted for demographic confounders, smoking status, and comorbidities.

Results: Among 1967 subjects, higher optimism was significantly associated with older age, non-Hispanic white race, marital status, quitting smoking status, absence of COPD, and absence of depression. In multivariable analysis, higher optimism was independently associated with fewer prior exacerbations of COPD (coef $=-0.037, \mathrm{P}<0.001)$. Higher optimism was also related to better MMRC scores (coef $=-0.041, P<0.001)$, CAT scores (coef $=-0.391, P<0.001$ ), SGRQ scores (coef $=-0.958, \mathrm{P}<0.001), \mathrm{BODE}$ index (coef $=-0.059, \mathrm{P}<0.001)$, and longer 6 -min walk distance $($ coef $=10.227, P<0.001)$. After stratification by severity of COPD, these associations with optimism were still significant in all groups. No significant association was observed for cross-sectional FEV (\%) or FVC (\%) with optimism score.

Interpretation: Fewer exacerbations and less severe respiratory symptoms and higher functional capacity were associated with higher optimism, which may impact health outcomes in current and former smokers with and without COPD. Optimism is a modifiable trait and these results may further support a role for CBT to improve outcomes in COPD.
\end{abstract}

Keywords: Optimism, COPD, Exacerbation, Dyspnea, Quality of life

\section{Introduction}

*Correspondence: redld@channing.harvard.edu

${ }^{1}$ Channing Division of Network Medicine, Brigham and Women's Hospital, 181 Longwood Avenue, Boston, MA 02115, USA

Full list of author information is available at the end of the article
Optimism is a personality trait characterized by the positive expectation that good things will happen in the future [1]. Empirical studies have described that individuals with higher optimism are more likely to be successful [2-6]. Optimism also contributes to health-promoting behaviors, such as smoking cessation, exercise, or healthy original author(s) and the source, provide a link to the Creative Commons licence, and indicate if changes were made. The images or other third party material in this article are included in the article's Creative Commons licence, unless indicated otherwise in a credit line to the material. If material is not included in the article's Creative Commons licence and your intended use is not permitted by statutory regulation or exceeds the permitted use, you will need to obtain permission directly from the copyright holder. To view a copy of this licence, visit http://creativecommons.org/licenses/by/4.0/. The Creative Commons Public Domain Dedication waiver (http://creativeco mmons.org/publicdomain/zero/1.0/) applies to the data made available in this article, unless otherwise stated in a credit line to the data. 
diet [2]. Inverse correlation between optimism and depressive symptoms has been observed [7, 8]. Moreover, positive associations between optimism and favorable physical health outcomes, especially related to cardiovascular events and all-cause mortality, were reported in a recent meta-analysis [9]. In the Nurses' Health Study, all-cause and cause-specific mortality rates were followed prospectively after measuring optimism scores, and women with higher optimism had lower all-cause and cause-specific mortality related to respiratory disease, cancer, heart disease, stroke, and infection [10].

The associations between optimism and pulmonary function were examined prospectively during an average of 8 years of follow-up in the Veterans Administration Normative Aging Study; men with higher optimism had higher levels of lung function and slower rate of lung function decline [11]. Patients with Chronic Obstructive Pulmonary Disease (COPD) often have comorbidities which significantly impact disease course including frequent hospitalization and premature death [12]. Among the comorbidities, depression and anxiety contribute to the burden of COPD and deleterious effects on social functioning, quality of life, and healthcare utilization [13-15]. Furthermore, symptoms of depression and anxiety often overlap with those of COPD, making these comorbid conditions difficult to identify [16]. Though optimism is associated with depression and anxiety [17], the positive health effects of optimism are independent of these psychosocial factors [9-11].

Optimism is partially heritable [18], but also influenced by social structural factors [19]. Several randomized trials have suggested that cognitive behavioral therapy can modify optimism and improve quality of life [20-25]. Nevertheless, the assessment of optimism in clinical practice is uncommon, but represents a potential clinical intervention point for cognitive behavioral therapy to improve outcomes in chronic respiratory diseases. Furthermore, the influence of optimism on lung diseases has not been researched extensively. The aim of our study was to determine the association of higher optimism with less respiratory symptoms and better functional capacity in current and former smokers with and without COPD.

\section{Materials and methods}

\section{Study design and population}

Participants from the 10-year follow-up visit for the Genetic Epidemiology of COPD (COPDGene) cohort were included in the current analysis $(\mathrm{N}=1967$, data freeze March 20th, 2020, pre-pandemic data). Study design of the COPDGene cohort has been described previously [26]. Briefly, COPDGene is a multicenter observational cohort of non-Hispanic white or African-American current and former smokers in the US, aged between 45 and 80 years at enrollment, with at least 10 pack-years of cigarette smoking. All participants provided written informed consent, and approval was obtained from all 21 local institutional review boards. COPD was diagnosed and classified by the Global Initiative for Chronic Obstructive Lung Disease (GOLD) guidelines [27].

\section{Measurements}

Questionnaires were used to assess sociodemographic information, respiratory symptoms, and medical history at baseline and follow-up visits. Sociodemographic information included age, sex, race, marital status, and smoking history. Respiratory symptoms and health status were assessed using the modified Medical Research Council (mMRC) questionnaire on breathlessness [28, 29], COPD Assessment Test (CAT) [30], and Saint George's Respiratory Questionnaire (SGRQ) for quality of life (written permission for the use of this tool by COPDGene obtained in 2010) [31]. Higher scores on the SGRQ denote worse quality of life (instrument has not been modified). Exacerbation risk was determined by self-reported history in the previous 12 months and severe exacerbation was defined as requiring a visit to the emergency room or hospitalization. Spirometry and 6-min walk distance tests were performed at each visit according to standard techniques [32, 33], and the BODE index was calculated using these measurements [34]. GOLD grade for airflow limitation was classified using post-bronchodilator spirometry among subjects with forced expiratory volume in $1 \mathrm{~s}\left(\mathrm{FEV}_{1}\right) /$ forced vital capacity $(\mathrm{FVC})<0.7$ : GOLD $1, \mathrm{FEV}_{1} \geq 80 \%$ predicted; GOLD 2, $50 \% \leq \mathrm{FEV}_{1}<80 \%$ predicted; GOLD 3, $30 \% \leq \mathrm{FEV}_{1}<50 \%$ predicted; and GOLD 4, $\mathrm{FEV}_{1}<30 \%$ predicted [27]. Subjects with Preserved Ratio Impaired Spirometry (PRISm) were defined as having $\mathrm{FEV}_{1} / \mathrm{FVC} \geq 0.7$ and $\mathrm{FEV}_{1}<80 \%$ predicted. Smokers with normal spirometry were defined by $\mathrm{FEV}_{1} / \mathrm{FVC}>0.7$ and $\mathrm{FEV}_{1}>80 \%$ predicted. Optimism was measured at the 10-year follow-up visit using the Life Orientation Test-Revised (LOT-R) [35] which is composed of 6 validated items: three items to assess optimism and three items to assess pessimism. Each item is on a Likert scale (score options $0-4$ ), and the total score is calculated by adding the optimism question scores and inverted pessimism question scores, as published previously [35]. Total score ranges from 0 to 24, and higher scores indicate higher optimism. To assess the possibility of discontinuous or threshold effects, quartiles of optimism based on score distributions were created. Depression and anxiety were assessed as self-reported history of doctor-diagnosed depression and anxiety. The Hospital Anxiety and Depression Scale (HADS), which can measure both anxiety and depression in a general medical 
population, was also obtained [36]. HADS is composed of 7 items for depression, with each item ranging from 0 to 3 , with total scores ranging from 0 to 21 . We used the cut-off value of HADS score of 8 points to categorize depression at the time of study visit evaluation. A flow chart summarizing the covariates and predictors at each study phase is provided (Additional file 1: Fig. S1).

\section{Statistical analysis}

Subject characteristics are presented as means $( \pm S D)$ for continuous variables and as relative frequencies for categorical variables. Means were compared using a t-test or analysis of variance (ANOVA), and categorical variables were compared using a chi-squared or Fisher's exact test. Univariable analysis for association between variables and optimism was performed stratified according to GOLD stage. For the occurrence of severe exacerbations and number of exacerbations, logistic regression models and Poisson regression models were used, respectively. For the MMRC, CAT, SGRQ, and 6-min walk distance, linear regression was used for each model. To evaluate multivariable associations with optimism, two models were evaluated. Model 1 adjusted for demographics (DM) including age, sex, race, and marital status and added health behavior factors (HB): body mass index (BMI) and current smoking status as potential confounders $(\mathrm{DM}+\mathrm{HB})$. Model 2 further adjusted for health conditions (HC) adding presence of depression, hypertension, diabetes mellitus, and $\mathrm{FEV}_{1}$ (\% predicted) to model 1 $(\mathrm{DM}+\mathrm{HB}+\mathrm{HC})$. Optimism score was examined both as a continuous and as a categorical variable (quartiles). Regression models for the association of optimism with lung function including $\mathrm{FEV}_{1}$ (\% predicted) or FVC (\% predicted) were adjusted for age, sex, race, marital status, BMI, current smoking status, presence of depression, hypertension, and diabetes mellitus in model 2 . To evaluate whether functional status would predict optimism at visit 3, values of MMRC, CAT, SGRQ score, or 6-min walk distance at visit 2 (5 years) or visit 1 (baseline) were adjusted for age, sex, race, marital status, BMI, current smoking status, history of depression, presence of hypertension, diabetes mellitus, and $\mathrm{FEV}_{1}$ (\% predicted) at visit 2 or visit 1 , respectively. BODE index models excluded variables for BMI and $\mathrm{FEV}_{1}$ (\% predicted) in model 2. All the statistical analysis was performed using $\mathrm{R}$ (version 3.6.0).

\section{Results}

A total of 1967 subjects returned for the ten-year follow-up of COPDGene as of March 2020 (pre-pandemic shutdown), consisting of 812 without spirometric airflow limitation, 241 GOLD 1, 384 GOLD 2, 193 GOLD 3, 101 GOLD 4, and 236 PRISm. Demographic and clinical characteristics of these participants are summarized in Table 1. Mean optimism scores according to spirometry stage were $18.9,18.3,17.8$, and 17.6 for normal spirometry, GOLD 1, GOLD 2-4, and PRISm, respectively. Subjects with COPD GOLD 2-4 presented with lower optimism than those with normal spirometry (coef $=-0.915, \mathrm{P}<0.001)$. Higher optimism score was associated with advanced age, non-Hispanic white race, being married, former smoking status, and absence of depression or anxiety in all stratified groups in univariable analysis. However, there was no significant association with pulmonary function including $\mathrm{FEV}_{1}$ (\% predicted) and FVC (\% predicted) in all stratified groups (Table 2). Significant associations between higher optimism score with fewer respiratory symptoms and better MMRC, CAT, SGRQ score, 6-min walk distance, and BODE index were present in univariable analysis (Table 2 and Figs. 1, 2). Fewer and less severe prior COPD exacerbations were observed in the 3rd and 4th highest optimism quartile groups in univariable analysis (Table 3). For the prior severe exacerbation events, in model 1 adjusted for demographics and health behavior $(\mathrm{DM}+\mathrm{HB})$, these associations remained significant, but in model 2, after further adjustment for other health conditions $(\mathrm{DM}+\mathrm{HB}+\mathrm{HC})$, the association was attenuated but the effect was in the same direction. For the number of prior exacerbations, model $1(\mathrm{DM}+\mathrm{HB})$ was significant in the 2nd, 3rd, and 4th optimism quartile groups compared to the lowest quartile. In model 2 $(\mathrm{DM}+\mathrm{HB}+\mathrm{HC})$, the associations were substantially attenuated but remained significant in the 3rd and 4th quartile: high optimism group. Higher frequency of prior history of exacerbations was significantly associated with lower optimism score as a continuous value (Table 3). For the functional outcomes, higher optimism was independently associated with less severe MMRC $(\operatorname{coef}=-0.041$, $\mathrm{P}<0.001)$, CAT (coef $=-0.391, \mathrm{P}<0.001)$, and total SGRQ score $(\operatorname{coef}=-0.958, \quad \mathrm{P}<0.001)$ including all scores of each domain (activity domain, coef $=-1.125$, $\mathrm{P}<0.001$; impact domain, $\quad$ coef $=-0.908, \quad \mathrm{P}<0.001$; symptom domain, coef $=-0.759, \quad \mathrm{P}<0.001), \quad \mathrm{BODE}$ index (coef $=-0.059, \mathrm{P}<0.001)$, and higher 6 -min walk distance ( $\operatorname{coef}=10.227, \mathrm{P}<0.001)$ in the fully adjusted model.

\section{Associations between optimism and COPD}

We stratified the study population according to severity of airflow limitation as normal spirometry, GOLD 2-4, and PRISm groups using GOLD grade, and evaluated the association of optimism with MMRC score, CAT score, all domains of SGRQ score, 6-min walk distance, and BODE index-all were statically significant in the stratified groups (Table 4). Detailed results of each model are 
Table 1 Characteristics of study participants

\begin{tabular}{|c|c|c|c|c|c|c|}
\hline & $\begin{array}{l}\text { Normal } \\
\text { spirometry } \\
(\mathrm{N}=812)\end{array}$ & GOLD $1(N=241)$ & GOLD 2-4 (N=678) & PRISm (N=236) & $\begin{array}{l}\text { P-value (normal } \\
\text { vs. GOLD 2-4) }\end{array}$ & $\begin{array}{l}\text { P-value } \\
\text { (normal vs } \\
\text { PRISm) }\end{array}$ \\
\hline Age & $67.32 \pm 8.07$ & $71.77 \pm 9.01$ & $71.27 \pm 8.10$ & $65.27 \pm 7.33$ & $<0.001$ & $<0.001$ \\
\hline Female sex (n, \%) & 438 (53.9\%) & $112(46.5 \%)$ & $319(47.1 \%)$ & $126(53.4 \%)$ & 0.009 & 0.940 \\
\hline White race (n, \%) & $550(67.7 \%)$ & $184(76.3 \%)$ & $526(77.6 \%)$ & $120(50.8 \%)$ & $<0.001$ & $<0.001$ \\
\hline BMI (mean \pm SD) & $28.78 \pm 5.88$ & $26.86 \pm 5.31$ & $27.83 \pm 6.37$ & $32.05 \pm 7.02$ & 0.003 & $<0.001$ \\
\hline Marital status & & & & & 0.248 & 0.005 \\
\hline Married & $349(43.0 \%)$ & $107(44.4 \%)$ & $276(40.7 \%)$ & $64(27.1 \%)$ & & \\
\hline Divorced & $190(23.4 \%)$ & $51(21.2 \%)$ & $175(25.8 \%)$ & $61(25.8 \%)$ & & \\
\hline Widowed & $70(8.6 \%)$ & $38(15.8 \%)$ & $96(14.2 \%)$ & $33(14.0 \%)$ & & \\
\hline Separated & $23(2.8 \%)$ & $4(1.7 \%)$ & $13(1.9 \%)$ & $9(3.8 \%)$ & & \\
\hline Never & $156(19.2 \%)$ & $34(14.1 \%)$ & $108(15.9 \%)$ & $67(28.4 \%)$ & & \\
\hline Unmarried couple & $22(2.7 \%)$ & $7(2.9 \%)$ & $10(1.5 \%)$ & $2(0.8 \%)$ & & \\
\hline Current smoker & $322(39.7 \%)$ & $92(38.2 \%)$ & $246(36.3 \%)$ & $118(50.0 \%)$ & 0.119 & 0.008 \\
\hline \multicolumn{7}{|l|}{ Comorbidities } \\
\hline Hypertension & $423(52.1 \%)$ & $137(56.8 \%)$ & $428(63.1 \%)$ & $158(66.9 \%)$ & $<0.001$ & $<0.001$ \\
\hline Diabetes & $160(19.7 \%)$ & $43(17.8 \%)$ & 130 (19.2\%) & $83(35.2 \%)$ & 0.848 & $<0.001$ \\
\hline Depression & $213(26.2 \%)$ & $55(22.8 \%)$ & $165(24.3 \%)$ & $76(32.2 \%)$ & 0.437 & 0.085 \\
\hline Anxiety & $159(19.6 \%)$ & $43(17.8 \%)$ & $135(19.9 \%)$ & $58(24.6 \%)$ & 0.925 & 0.115 \\
\hline HADS-depression & $2.68 \pm 2.91$ & $3.16 \pm 3.22$ & $3.85 \pm 3.15$ & $3.57 \pm 3.27$ & $<0.001$ & $<0.001$ \\
\hline HADS-anxiety & $3.57 \pm 3.43$ & $3.83 \pm 3.49$ & $4.03 \pm 3.64$ & $4.55 \pm 3.80$ & 0.012 & $<0.001$ \\
\hline \multicolumn{7}{|l|}{ Lung function } \\
\hline $\mathrm{FEV}_{1}(\%)$ & $99.45 \pm 13.53$ & $92.59 \pm 10.47$ & $51.75 \pm 17.24$ & $69.42 \pm 8.52$ & $<0.001$ & $<0.001$ \\
\hline FVC (\%) & $96.90 \pm 13.22$ & $108.78 \pm 14.87$ & $75.89 \pm 17.87$ & $69.94 \pm 9.57$ & $<0.001$ & $<0.001$ \\
\hline $\mathrm{FEV}_{1} / \mathrm{FVC}$ & $0.78 \pm 0.05$ & $0.64 \pm 0.05$ & $0.51 \pm 0.12$ & $0.76 \pm 0.05$ & $<0.001$ & $<0.001$ \\
\hline
\end{tabular}

summarized (Additional file 1: Table S1). Effects sizes were slightly attenuated but the directions of effect were similar regardless of adjustment for doctor-diagnosed history of depression or adjustment using cut-off value of HADS (Additional file 1: Table S2). To address potential concerns regarding residual confounding between optimism and depression, we repeated the same analysis excluding respondents with previous history of depression. Association between optimism and MMRC, CAT score, all domains of SGRQ score, 6-min walk distance and BODE index were still significant in the presence of COPD (GOLD 1-4). In subjects with normal spirometry, association with CAT score and SGRQ score remained robust after the most stringent removal of subjects with previous history of depression (Additional file 1: Tables S3 and S4). No significant associations between optimism score and lung function were observed for the multivariable analysis (Table 4 and Additional file 1: Tables S1-S3).

\section{Associations between optimism and PRISm}

Baseline characteristics of PRISm subjects are summarized in Table 1. The associations between higher optimism score and functional capacities were in the same direction as for COPD subjects. In multivariable analysis, all these outcomes remained significant but suggested stronger association in PRISm subjects, especially for 6-min walk distance. Results of the sensitivity analysis excluding subjects with history of doctor-diagnosed depression are summarized (Additional file 1: Table S3). After adjustment for cut-off value of HADS instead of previous history of depression diagnosis, the results were similar (Additional file 1: Tables S2 and S4).

\section{Predictive variables for future optimism}

Values of MMRC, CAT, SGRQ score, 6-min walk distance and BODE index at visit 1 and 2 were significantly associated with optimism scores at visit 3 in multivariable analysis, and changes of MMRC, CAT, SGRQ score, and BODE index 5 and 10 years previously were also significantly associated with visit 3 optimism in smokers with and without COPD (Additional file 1: Table S5). The association between visit 2 functional variables and visit 3 optimism scores were examined at each group stratified by GOLD grade. CAT, SGRQ score and 6-min walk distance were significant predictors for optimism score at visit 3 in all groups. For GOLD 2-4 groups, decline 
Table 2 Univariable analysis for optimism score

\begin{tabular}{|c|c|c|c|c|c|c|c|c|c|c|}
\hline \multirow[t]{2}{*}{ Optimism score } & \multicolumn{2}{|c|}{ Total $(\mathrm{N}=1967)$} & \multicolumn{2}{|c|}{$\begin{array}{l}\text { Normal spirometry } \\
(\mathrm{N}=812)\end{array}$} & \multicolumn{2}{|c|}{ GOLD $1(\mathrm{~N}=241)$} & \multicolumn{2}{|c|}{ GOLD 2-4 (N=678) } & \multicolumn{2}{|c|}{ PRISm (N=236) } \\
\hline & Coef. & P-value & Coef. & P-value & Coef. & P-value & Coef. & P-value & Coef. & P-value \\
\hline Age & 0.109 & $<0.001$ & 0.107 & $<0.001$ & 0.104 & 0.003 & 0.146 & $<0.001$ & 0.154 & $<0.001$ \\
\hline Female Sex & 0.296 & 0.173 & 0.632 & 0.049 & -0.186 & 0.769 & 0.123 & 0.750 & -0.222 & 0.730 \\
\hline White race & 1.951 & $<0.001$ & 2.112 & $<0.001$ & 2.916 & $<0.001^{5}$ & 1.653 & $<0.001$ & 1.82 & 0.004 \\
\hline $\mathrm{BMI}$ & -0.006 & 0.722 & 0.061 & 0.026 & -0.100 & 0.093 & -0.028 & 0.348 & -0.038 & 0.399 \\
\hline Marital status ${ }^{a}$ & 0.440 & $<0.001$ & 1.264 & $<0.001$ & 2.127 & $<0.001$ & 1.200 & 0.002 & 1.546 & 0.017 \\
\hline Current smoking & -2.004 & $<0.001$ & -2.212 & $<0.001$ & -0.994 & 0.131 & -2.076 & $<0.001$ & -2.156 & $<0.001$ \\
\hline \multicolumn{11}{|l|}{ Comorbidities } \\
\hline Depression & -2.670 & $<0.001$ & -1.839 & $<0.001$ & -2.857 & $<0.001$ & -3.538 & $<0.001$ & -2.927 & $<0.001$ \\
\hline Anxiety & -2.529 & $<0.001$ & -1.782 & $<0.001$ & -2.725 & $<0.001$ & -3.160 & $<0.001$ & -2.805 & $<0.001$ \\
\hline HADS-depression & -0.804 & $<0.001$ & -0.724 & $<0.001$ & -0.871 & $<0.001$ & -0.887 & $<0.001$ & -0.697 & $<0.001$ \\
\hline HADS-anxiety & -0.675 & $<0.001$ & -0.575 & $<0.001$ & -0.806 & $<0.001$ & -0.750 & $<0.001$ & -0.593 & $<0.001$ \\
\hline Hypertension & -0.586 & 0.008 & -0.732 & 0.022 & -1.040 & 0.103 & 0.023 & 0.953 & -0.288 & 0.672 \\
\hline Diabetes & -1.105 & $<0.001$ & -0.799 & 0.047 & -1.961 & 0.017 & -1.090 & 0.025 & -0.944 & 0.158 \\
\hline \multicolumn{11}{|l|}{ Lung function } \\
\hline $\mathrm{FEV}_{1}(\%$ predict $)$ & 0.020 & $<0.001$ & 0.016 & 0.182 & -0.025 & 0.408 & 0.020 & 0.075 & 0.008 & 0.826 \\
\hline FVC (\% predict) & 0.016 & 0.004 & 0.003 & 0.828 & -0.037 & 0.084 & 0.013 & 0.241 & -0.015 & 0.647 \\
\hline $\mathrm{FEV}_{1} / \mathrm{FVC}$ & 2.159 & 0.003 & -0.227 & 0.943 & 0.352 & 0.956 & 0.829 & 0.595 & -1.412 & 0.837 \\
\hline \multicolumn{11}{|l|}{ Functional status } \\
\hline MMRC & -0.768 & $<0.001$ & -0.727 & $<0.001$ & -1.249 & $<0.001$ & -0.644 & $<0.001$ & -1.030 & $<0.001$ \\
\hline CAT & -0.201 & $<0.001$ & -0.183 & $<0.001$ & -0.261 & $<0.001$ & -0.214 & $<0.001$ & -0.195 & $<0.001$ \\
\hline SGRQ & -0.078 & $<0.001$ & -0.075 & $<0.001$ & -0.118 & $<0.001$ & -0.079 & $<0.001$ & -0.093 & $<0.001$ \\
\hline $6 \mathrm{MWD}$ & $1.98 \mathrm{E}-03$ & $<0.001$ & 0.002 & $<0.001$ & 0.002 & 0.015 & 0.001 & 0.007 & 0.003 & $<0.001$ \\
\hline BODE & -0.493 & $<0.001$ & -0.821 & $<0.001$ & -1.384 & $<0.001$ & -0.321 & $<0.001$ & -1.011 & $<0.001$ \\
\hline
\end{tabular}

${ }^{a}$ Marital status: divorced, separated, never, unmarried couple status compared to married or widowed status; Optimism scores are examined as continuous variable

of CAT, or SGRQ score between visit 2 and visit 3 were associated with lower optimism score at visit 3. Association of optimism score with visit 1 functional capacities and their changes are also summarized in Additional file 1: Table S5. In the PRISm population, MMRC, CAT, SGRQ score, 6-min walk distance, and BODE index at visit 2 were all significant predictor for optimism score at visit 3 , but no significant association was observed for changes during follow-up.

\section{Discussion}

We found significant associations between optimism and respiratory symptoms and functional status including MMRC, CAT score, SGRQ score, 6-min walk distance, and BODE index in the presence or absence of COPD in current and former smokers. Higher optimism was related to fewer respiratory symptoms, less frequent report of prior exacerbations of COPD, higher exercise capacity, and better quality of life. Optimism is a modifiable factor, with strong associations with health status and mortality. It is well known that respiratory symptoms or quality of life in COPD correlate poorly with lung function [37]. Cognitive behavioral therapy (CBT) for patients with COPD has been suggested to improve their anxiety, depression [38], breathlessness [39], and quality of life [40]. Traditional CBT for mood disorders focuses on problem solving. However, positive CBT for optimism focuses on feeling positive emotion, being engaged at home and work, and experiencing positive relationships and accomplishments [41]; investigating optimism may provide an innovative intervention opportunity in conjunction with pulmonary rehabilitation to improve quality of life and outcomes in COPD [42].

Severity of COPD is classified based on occurrence of exacerbations in the past 12 months and functional status including symptoms and quality of life, in addition to lung function [27]. Our study revealed that a positive outlook may impact COPD functional outcomes; addressing psychosocial aspects of COPD constitutes an important and undertreated aspect of COPD management. Psychological factors may exert their effects by both the indirect behavioral mechanisms and the direct physiologic mechanisms [43]. Physical activity, healthier diet, and smoking cessation are favorable health behaviors associated with 

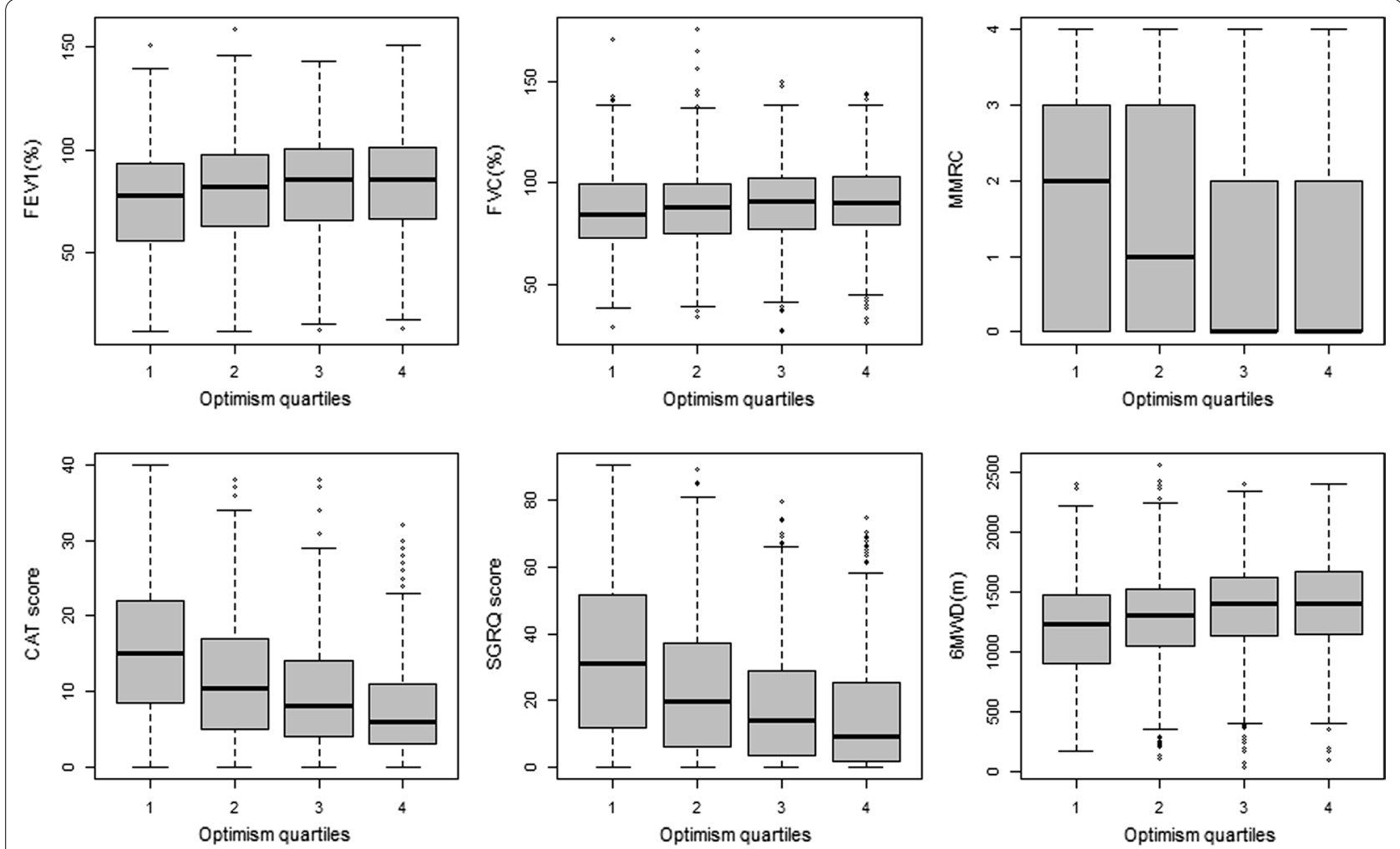

Fig. 1 Univariable comparison of lung function and functional capacities among optimism quartiles
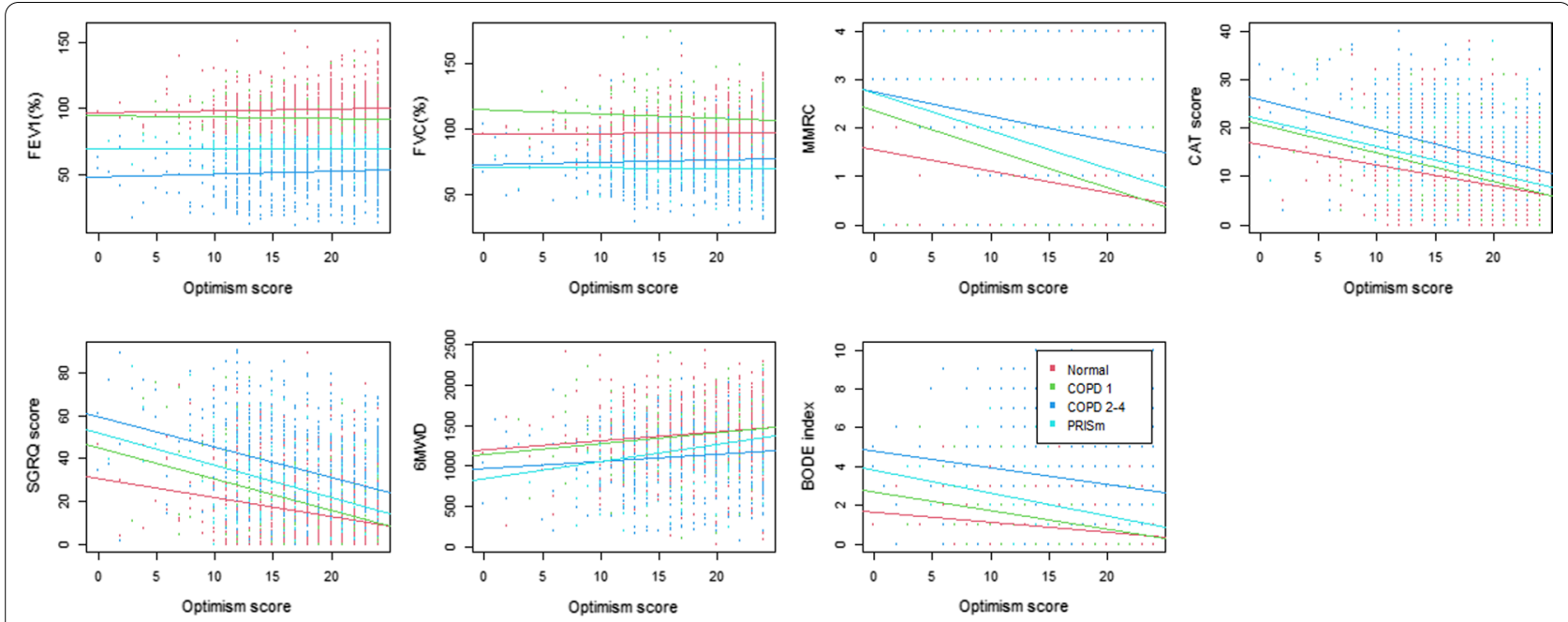

Fig. 2 Correlation of lung function and functional capacities with optimistic score stratified by severity of airflow limitation

optimism [44]. More active problem-solving tendencies of optimistic people may be advantageous to mitigate risk of exacerbation, cope with and relieve stress, and promote better overall health quality [45]. In addition, optimism may impact medication compliance for stable
COPD. Furthermore, optimism could potentially influence COPD pathobiology directly through modulation of immune function [46, 47] by various mediators [48, 49]. Since COPD is a chronic inflammatory lung disease, those pathophysiologic mechanisms could directly affect 
Table 3 Association of optimism and past exacerbation history of COPD in all subjects

\begin{tabular}{|c|c|c|c|c|c|c|c|c|}
\hline \multirow[t]{2}{*}{ Severe exacerbation } & \multicolumn{2}{|c|}{$\begin{array}{l}\text { Q2 vs. Q1 for optimism } \\
\text { score }\end{array}$} & \multicolumn{2}{|c|}{$\begin{array}{l}\text { Q3 vs. Q1 for optimism } \\
\text { score }\end{array}$} & \multicolumn{2}{|c|}{$\begin{array}{l}\text { Q4 vs. Q1 for optimism } \\
\text { score }\end{array}$} & \multicolumn{2}{|c|}{$\begin{array}{l}\text { Optimism as a } \\
\text { continuous variable }\end{array}$} \\
\hline & OR & $95 \% \mathrm{Cl}$ & OR & $95 \% \mathrm{Cl}$ & OR & $95 \% \mathrm{Cl}$ & OR & $95 \% \mathrm{Cl}$ \\
\hline Unadjusted & 0.695 & $0.465-1.039$ & 0.457 & $0.286-0.729$ & 0.530 & $0.341-0.824$ & 0.943 & $0.914-0.972$ \\
\hline $\mathrm{DM}+\mathrm{HB}$ & 0.686 & $0.454-1.036$ & 0.462 & $0.289-0.748$ & 0.525 & $0.330-0.835$ & 0.941 & $0.911-0.971$ \\
\hline $\mathrm{DM}+\mathrm{HB}+\mathrm{HC}$ & 0.869 & $0.561-1.344$ & 0.685 & $0.411-1.142$ & 0.792 & $0.481-1.302$ & 0.970 & $0.936-1.005$ \\
\hline Exacerbation frequency & Coef. & P-value & Coef. & P-value & Coef. & P-value & Coef. & P-value \\
\hline Unadjusted & -0.325 & 0.005 & -0.665 & $5.55 \times 10^{-7}$ & -0.863 & $6.23 \times 10^{-10}$ & -0.061 & $2.85 \times 10^{-12}$ \\
\hline $\mathrm{DM}+\mathrm{HB}$ & -0.354 & 0.002 & -0.756 & $2.32 \times 10^{-8}$ & -0.992 & $5.46 \times 10^{-12}$ & -0.068 & $1.48 \times 10^{-14}$ \\
\hline $\mathrm{DM}+\mathrm{HB}+\mathrm{HC}$ & -0.088 & 0.457 & -0.334 & 0.017 & -0.542 & $2.69 \times 10^{-4}$ & -0.037 & $1.39 \times 10^{-4}$ \\
\hline
\end{tabular}

Q4: most optimistic

Demographic: Age, sex, race, marital status

Health Behavior: BMI, smoking status

Health condition: Depression, hypertension, diabetes, $\mathrm{FEV}_{1}$ (\% predicted)

Table 4 Multivariate association of optimism with lung function and functional outcomes (Model 2)

\begin{tabular}{|c|c|c|c|c|c|c|c|c|}
\hline & \multicolumn{2}{|c|}{ Normal spirometry } & \multicolumn{2}{|l|}{ GOLD 1} & \multicolumn{2}{|c|}{ GOLD 2-4 } & \multicolumn{2}{|l|}{ PRISm } \\
\hline & Coef. & P-value & Coef. & P-value & Coef. & P-value & Coef. & P-value \\
\hline $\mathrm{FEV}_{1}(\%$ predicted $)$ & 0.055 & 0.611 & -0.256 & 0.700 & 0.319 & 0.025 & -0.034 & 0.785 \\
\hline FVC (\% predicted) & 0.055 & 0.611 & -0.460 & 0.023 & 0.175 & 0.241 & -0.076 & 0.586 \\
\hline MMRC score & -0.031 & $<0.001$ & -0.051 & $<0.001$ & -0.038 & $<0.001$ & -0.048 & 0.008 \\
\hline CAT score & -0.278 & $<0.001$ & -0.390 & $<0.001$ & -0.430 & $<0.001$ & -0.429 & $<0.001$ \\
\hline SGRQ Total score & -0.669 & $<0.001$ & -1.038 & $<0.001$ & -1.014 & $<0.001$ & -1.103 & $<0.001$ \\
\hline SGRQ Activity & -0.951 & $<0.001$ & -1.205 & $<0.001$ & -0.966 & $<0.001$ & -1.433 & $<0.001$ \\
\hline SGRQ Impact & -0.511 & $<0.001$ & -0.959 & $<0.001$ & -1.141 & $<0.001$ & -0.940 & $<0.001$ \\
\hline SGRQ Symptoms & -0.639 & $<0.001$ & -0.954 & $<0.001$ & -0.595 & $<0.001$ & -0.995 & 0.003 \\
\hline 6-min walk distance & 9.585 & $<0.001$ & 8.639 & 0.092 & 7.958 & 0.004 & 17.509 & $<0.001$ \\
\hline BODE index & -0.036 & $<0.001$ & -0.070 & $<0.001$ & -0.053 & $<0.001$ & -0.079 & $<0.001$ \\
\hline
\end{tabular}

Adjusted by age, sex, race, marital status, BMI, current smoking status, presence of depression, hypertension, diabetes, and FEV ${ }_{1}(\%$ predicted)

functional capacities and pulmonary outcomes. Heritability of optimism has been estimated as $25 \%$ [18]; in other words, although having genetic features optimism can be learned and influenced by underlying health conditions. However, optimism also demonstrates stability across a long span of time without intervention [50], and has been associated with positive health effects in many prospective studies.

There are limitations to our current study. It is not clear whether the association of optimism with functional outcomes is a cause or effect of prior respiratory status. We cannot completely rule out the possibility that a confounding factor links optimism and functional outcomes, although we adjusted for several potential confounders, especially depression, in multiple ways and these results remained robust after stringent adjustment for depression. Optimism scores were only available at the 10-year follow-up visit, so we could not assess impact of optimism score prospectively. A published prospective study described men with higher optimism associated with higher lung function and slower rate of lung function decline over course of follow-up in the Normative Aging Study [9]. However, we did not observe a longitudinal relationship between prior lung function decline and optimism in our study population. Given that subjects in COPDGene were ascertained to have high smoking histories and more severe COPD subjects, our results may not be generalizable to the general population. In addition, our study included non-Hispanic white and African Americans, and therefore might not be generalized to Hispanic or Asian individuals with a history of smoking.

In summary, higher dispositional optimism is associated with fewer COPD exacerbations and better functional status in smokers with and without COPD. Future 
research should be focused upon replicating our findings, but these results may further support a role of cognitive behavioral therapy to improve outcomes for COPD.

\begin{abstract}
Abbreviations
BMI: Body mass index; CAT: COPD Assessment Test; CBT: Cognitive behavioral therapy; COPD: Chronic Obstructive Pulmonary Disease; COPDGene: Genetic Epidemiology of COPD; FEV 1 : Forced expiratory volume in $1 \mathrm{~s} ;$ FVC: Forced vital capacity; GOLD: Global Initiative for Chronic Obstructive Lung Disease HADS: Hospital Anxiety and Depression Scale; LOT-R: The Life Orientation TestRevised; mMRC: Modified Medical Research Council; PRISm: Preserved Ratio Impaired Spirometry; SGRQ: Saint George's Respiratory Questionnaire.
\end{abstract}

\section{Supplementary Information}

The online version contains supplementary material available at https://doi. org/10.1186/s12931-021-01922-6.

Additional file 1: Table S1. Multivariate association of optimism with lung function and functional outcomes with 2 tier model. Table S2. HADS adjustment instead of previous history of depression diagnosis. Table S3. Sensitivity analysis excluding subjects with history of depression. Table S4. Sensitivity analysis excluding collection of subjects with previous history of depression and present depression by HADS. Table S5. Association of disease-related characteristics at previous visits as predictor of optimism score in next visit. Fig. S1. Flow chart of enrollment of COPDGene study population.

\section{Acknowledgements}

None applicable.

\section{Financial disclosure}

DLD reports grants from NIH and Bayer and honoraria from Novartis. EKS has received grant support from GlaxoSmithKline and Bayer.

\section{Authors' contributions}

Guarantor: DLD. HKK and DLD conceived of the analysis. HKK performed all analysis. EKS and DLD supervised the research project. HKK and DLD drafted the manuscript. KFH, BJM, EAR, and JDC provided data collection, substantial review for manuscript. All authors read and approved the final manuscript.

\section{Funding}

The project described was supported by Award Number U01 HL089897 and Award Number U01 HL089856 from the National Heart, Lung, and Blood Institute. The content is solely the responsibility of the authors and does not necessarily represent the official views of the National Heart, Lung, and Blood Institute or the National Institutes of Health. DLD is supported by P01 HL132825, R21 HL156122, R01 AG053273, an Alpha-1 Foundation Award, and a BWH Connors Center IGNITE First in Women Precision Medicine Award. COPDGene is also supported by the COPD Foundation through contributions made to an Industry Advisory Board that has included AstraZeneca, Bayer Pharmaceuticals, Boehringer-Ingelheim, Genentech, GlaxoSmithKline, Novartis, Pfizer, and Sunovion.

\section{Availability of data and materials}

COPDGene data are available through dbGAP (dbGaP Study Accession: phs000179.v6.p2).

\section{Declarations}

Ethics approval and consent to participate

All participants provided written informed consent, and approval was obtained from all local institutional review boards.

\section{Consent for publication}

None applicable.

\section{Author details}

${ }^{1}$ Channing Division of Network Medicine, Brigham and Women's Hospital, 181 Longwood Avenue, Boston, MA 02115, USA. ${ }^{2}$ Division of Pulmonary and Critical Care Medicine, Ilsan Paik Hospital, Inje University College of Medicine, Ilsan, Republic of Korea. ${ }^{3}$ Department of Psychiatry, University of lowa Carver College of Medicine, lowa, USA. ${ }^{4}$ National Jewish Health, Denver, CO, USA. ${ }^{5}$ Division of Pulmonary and Critical Care Medicine, Brigham and Women's Hospital, Boston, MA, USA.

Received: 1 May 2021 Accepted: 28 December 2021

Published online: 29 January 2022

\section{References}

1. Scheier MF, Carver CS. Dispositional optimism and physical well-being: the influence of generalized outcome expectancies on health. J Pers. 1987:55(2):169-210.

2. Carver CS, Scheier MF. Dispositional optimism. Trends Cogn Sci. 2014:18:293-9.

3. Carver CS, Scheier MF, Segerstrom SC. Optimism. Clin Psychol Rev. 2010;30:879-89.

4. Peterson P, Park N, Kim ES. Can optimism decrease the risk of illness and disease among the elderly? Aging Health. 2012;8(1):5-8.

5. Rasmussen HN, Scheier MF, Greenhouse JB. Optimism and physical health: a meta-analytic review. Ann Behav Med. 2009;37:239-56.

6. Roy B, Diez-Roux AV, Seeman T, Ranjit N, Shea S, Cushman M. Association of optimism and pessimism with inflammation and hemostasis in the Multi-Ethnic Study of Atherosclerosis (MESA). Psychosom Med. 2010;72:134-40.

7. Chang EC, Sanna LJ. Optimism, pessimism, and positive and negative affectivity in middle-aged adults: a test of a cognitive-affective model of psychological adjustment. Psychol Aging. 2001;16(3):524-31.

8. Hart SL, Vella L, Mohr DC. Relationships among depressive symptoms, benefit-finding, optimism, and positive affect in multiple sclerosis patients after psychotherapy for depression. Health Psychol. 2008;27(2):230-8.

9. Ronzanski A, Bavishi C, Kubzansky LD, Cohen R. Association of optimism with cardiovascular event and all-cause mortality. JAMA Network Open. 2019;2(9):e1912200

10. Kim ES, Hagan KA, Grodstein F, DeMeo DL, De Vivo I, Kubzansky LD. Optimism and cause-specific mortality: a prospective cohort study. Am J Epidemiol. 2017;185(1):21-9.

11. Kubzansky LD, Wright RJ, Cohen S, Weiss S, Rosner B, Sparrow D. Breathing easy: a prospective study of optimism and pulmonary function in the normative aging study. Ann Behav Med. 2002;24(4):345-53.

12. Sode BF, Dahl M, Nordestgaard BG. Myocardial infarction and other comorbidities with chronic obstructive pulmonary disease: a Danish Nationwide study of 7.4 million individuals. Eur Heart J. 2011;32:2365-75.

13. Yohannes AM, Willgoss TG, Baldwin RC, Connolly MJ. Depression and anxiety in chronic heart failure and chronic obstructive pulmonary disease: prevalence, relevance, clinical implication and management principles. Int J Geriatr Psychiatry. 2010;25:1209-21.

14. Doyle T, Palmer S, Johnson J, Babyak MA, Smith P, Mabe S. Association of anxiety and depression with pulmonary-specific symptoms in chronic obstructive pulmonary disease. Int J Psychiatry Med. 2013;45(2):189-202.

15. Dalal AA, Shah M, Lunacsek O, Hanania NA. Clinical and economic burden of depression/anxiety in chronic obstructive pulmonary disease patients within a managed care population. COPD. 2011;8(4):293-9.

16. Willgoss TG, Yohannes AM. Anxiety disorders in patients with COPD: a systematic review. Respir Care. 2013;58:858-66.

17. Boelen PA, van den Bout J. Positive thinking in bereavement: is it related to depression, anxiety, or grief symptomatology? Psychol Rep. 2002;91:857-63.

18. Plomin R, Scheier MF, Bergeman CS, et al. Optimism, pessimism and mental health: a twin/adoption study. Pers Individ Dif. 1992;13(8):921-30.

19. Hinz A, Sander C, Glaesmer H, Brähler E, Zenger M, Hilbert A, Kocalevent RD. Optimism and pessimism in the general population: psychometric properties of the Life Orientation Test (LOT-R). Int J Clin Health Psychol. 2017;17(2):161-70. 
20. Peters ML, Flink IK, Boersma K, et al. Manipulating optimism: can imaging a best possible self be used to increase future expectancies? J Posit Psychol. 2010;5(3):204-11.

21. Meevissen YM, Peters ML, Alberts HJ. Become more optimistic by imagining a best possible self: effects of a two week intervention. J Behav Ther Exp Psychiatry. 2011;42(3):371-8.

22. Murphy SE, Clare O'Donoghue $\mathrm{M}$, Drazich EH, et al. Imagining a brighter future: the effect of positive imagery training on mood, prospective mental imagery and emotional bias in older adults. Psychiatry Res. 2015;230(1):36-43.

23. Gillham JE, Reivich KJ, Jaycox LH, et al. Prevention of depressive symptoms in schoolchildren: two-year follow-up. Psychol Sci. 1995;6(6):343-51.

24. Yu DL, Seligman MEP. Preventing depressive symptoms in Chinese children. Prev Treat. 2002;5(1):9.

25. Henriksson S, Anclair M, Hiltunen AJ. Effectiveness of cognitive behavioral therapy on health-related quality of life: an evaluation of therapies provided by trainee therapists. Scand J Psychol. 2016;57(3):215-22.

26. Regan EA, Hokanson JE, Murphy JR, et al. Genetic epidemiology of COPD (COPDGene) study design. COPD. 2010;7(1):32-43.

27. Global Initiative for Chronic Obstructive Lung Disease (GOLD). Global strategy for the diagnosis, management and prevention of COPD; 2017. www.goldcopd.com/guidelines-global-strategyfor-diagnosis-manag ement.html. Accessed 1 Nov 2019.

28. Jones PW, Adamek L, Nadeau G, Banik N. Comparisons of health status scores with MRC grades in COPD: implications for the GOLD 2011 classification. Eur Respir J. 2013;42(3):647-54.

29. Mahler DA, Wells CK. Evaluation of clinical methods for rating dyspnea. Chest. 1988;93(3):580-6.

30. Jones PW, Harding G, Berry P, Wiklund I, Chen WH, Kline LN. Development and first validation of the COPD Assessment Test. Eur Respir J. 2009;34(3):648-54.

31. Meguro M, Barley EA, Spencer S, Jones PW. Development and validation of an improved, COPD-specific version of the St. George Respiratory Questionnaire. Chest. 2007;132(2):456-63.

32. Standardization of Spirometry, 1994 Update. American Thoracic Society. Am J Respir Crit Care Med. 1995; 152(3):1107-1136

33. ATS Committee on Proficiency Standards for Clinical Pulmonary Function Laboratories. ATS statement: guidelines for the six-minute walk test. Am J Respir Crit Care Med. 2002;166(1):111-7.

34. Celli BR, Cote CG, Marin JM, et al. The body-mass index, airflow obstruction, dyspnea, and exercise capacity index in chronic obstructive pulmonary disease. N Engl J Med. 2004;350:1005-12.

35. Scheier MF, Carver CS, Bridges MW. Distinguishing optimism from neuroticism (and trait anxiety, self-mastery, and self-esteem): a re-evaluation of the Life Orientation Test. J Pers Soc Psychol. 1994;67:1063-78.

36. Zigmond AS, Snaith RP. The hospital anxiety and depression scale. Acta Psychiatr Scand. 1983;67:361-70.

37. Agusti A, Calverley PM, Celli B, et al. Evaluation of COPD Longitudinally to Identify Predictive Surrogate Endpoints (ECLIPSE) investigators. Characterisation of COPD heterogeneity in the ECLIPSE cohort. Respir Res. 2010;11:122.

38. Hynninen MJ, Bjerke N, Pallesen S, Bakke PS, Nordhus IH. A randomized controlled trial of cognitive behavioral therapy for anxiety and depression in COPD. Respir Med. 2010;104(7):986-94.

39. Livermore N, Dimitri A, Sharpe L, McKenzie DK, Gandevia SC, Butler JE. Cognitive behaviour therapy reduces dyspnoea ratings in patients with chronic obstructive pulmonary disease (COPD). Respir Physiol Neurobiol. 2015;216:35-42.

40. Ma RC, Yin YY, Wang YQ, Liu X, Xie J. Effectiveness of cognitive behavioural therapy for chronic obstructive pulmonary disease patients: a systematic review and meta-analysis. Complement Ther Clin Pract. 2019;38:101071.

41. Geschwind N, Arntz A, Bannink F, Peeters F. Positive cognitive behavior therapy in the treatment of depression: a randomized order withinsubject comparison with traditional cognitive behavior therapy. Behav Res Ther. 2019;116:119-30.

42. Farver-Vestergaard I, O'Toole MS, O'Connor M, et al. Mindfulness-based cognitive therapy in COPD: a cluster randomised controlled trial. Eur Respir J. 2018;51(2):170.

43. Rozanski A. Behavioral cardiology: current advances and future directions. J Am Coll Cardiol. 2014;64(1):100-10.
44. Scheier MF, Carver CS. Effects of optimism on psychological and physical well-being: theoretical overview and empirical update. Cogn Ther Res. 1992;16:201-28.

45. Kamen LP, Seligman MEP. Explanatory style and health. Curr Psychol Res Rev. 1987;6:207-18.

46. Kohut ML, Cooper MM, Nickolaus MS, et al. Exercise and psychosocial factors modulate immunity to influenza vaccine in elderly individuals. J Gerontol A Biol Sci Med Sci. 2002;57(9):M557-62.

47. Segerstrom SC, Sephton SE. Optimistic expectancies and cell-mediated immunity: the role of positive affect. Psychol Sci. 2010;21(3):448-55.

48. Romagnani S. TH1 and TH2 subsets: regulation of differentiation and the role in protection and immunopathology. Internal Arch Allergy Immunol. 1992;98:279-85.

49. McEwen BS, Stellar E. Stress and the individual: mechanisms leading to disease. Arch Intern Med. 1993;153:2093-101.

50. Burns MO, Seligman MEP. Explanatory style across the life span: evidence for stability over 52 years. J Pers Soc Psychol. 1989;56:471-7.

\section{Publisher's Note}

Springer Nature remains neutral with regard to jurisdictional claims in published maps and institutional affiliations.
Ready to submit your research? Choose BMC and benefit from:

- fast, convenient online submission

- thorough peer review by experienced researchers in your field

- rapid publication on acceptance

- support for research data, including large and complex data types

- gold Open Access which fosters wider collaboration and increased citations

- maximum visibility for your research: over 100M website views per year

At BMC, research is always in progress.

Learn more biomedcentral.com/submissions 